\title{
Have you been exercising lately? Testing the role of past behavior on exercise adherence
}

Journal of Health Psychology

I-12

(C) The Author(s) 2019

Article reuse guidelines:

sagepub.com/journals-permissions DOI: $10.1177 / \mid 359105319878243$

journals.sagepub.com/home/hpq

@SAGE

\section{Filipe Rodrigues',2 ${ }^{1 D}$, Diogo S Teixeira ${ }^{3}$, Luís Cid ${ }^{1,4}$ and Diogo Monteiro ${ }^{1,4}[G Q: 1]$}

\begin{abstract}
The purpose of this study was to test the effect of past behavior on future behavior, considering the motivational sequence proposed by the self-determination theory. The total sample was formed by 293 exercisers aged between 18 and $65(M=36.57 \pm S D=1 \mid .25)$ years. Participants completed a multi-section survey of motivational, emotional and cognitive-related variables, and exercise adherence was measured using computer records. Past behavior was found to offset the direct effect of intention on future behavior and the indirect effect of all other variables under analysis on intention, acting as a "buffer" variable for experienced gym members.
\end{abstract}

\section{Keywords}

autonomous motivation, enjoyment, exercise adherence, intention, needs satisfaction, past behavior, supportive behaviors

\section{Introduction}

The promotion of regular physical exercise is still one of the hardest challenges health and exercise professionals face every day. According to international surveys, exercise withdrawal episodes and drop-out rates remain high and have been increasing during the latest years (EC, 2018; PAC, 2019; WHO, 2019). As the number of physical inactive individual increases, so does the number of health issues, including the increase of chronic diseases rates, the decrease of physical fitness, and the increase of psychological conditions (Lee et al., 2012). In this regard, recent research has been concentrating on understanding what promotes long-time exercise adherence.

A search on literature using key-words "exercise," "adherence," "motives," and "behavior" shows that most of contemporary research has focused on the impact of motivational and cognitive determinants on predicting health-related outcomes. For instance, the impact of motivation on intention toward exercising has been pointed out as a crucial predictor to consider when measuring exercise participation (Rodrigues et al., 2019). However, the role of past behavior as predictor of intention and future behavior has been

\footnotetext{
'University of Beira Interior, Portugal

${ }^{2}$ Research Center in Sports, Health Sciences and Human Development (CIDESD), Portugal

${ }^{3}$ Lusófona University, Portugal

${ }^{4}$ Sport Science School of Rio Maior (ESDRM-IPSantarém), Portugal
}

\section{Corresponding author:}

Filipe Rodrigues, University da Beira Interior, Rua Marquês de Ávila e Bolama, 620I-00I Covilhã, Portugal.

Email: ptfiliperodrigues@gmail.com 
given little attention (Hagger, 2019; Sommer, 2011) and virtually no consideration at all when it comes to the context of physical exercise. Despite this fact, theorists have shown past behavior to be a powerful predictor of future behavior, as it is understood as the way someone acted or reacted in response to external or internal cues in the past (Sheeran et al., 1999). The frequency of a certain behavior plays an important role and its repetition seems to lead to a state of "routine behavior," making the behavior an essential part of personal self (Sheeran and Webb, 2016). Therefore, examination of past behavior is paramount for researchers on assessing exercise-related outcomes and for fitness professionals to understand how to approach gym clients according to their exercise experience.[AQ: 1]

\section{Theoretical framework}

Over the past decades, the self-determination theory (SDT; Deci and Ryan, 1985) has proven to be a robust framework when analyzing the impact of motivational antecedents on physical exercise participation (Rodrigues et al., 2018). Specifically, it focuses on assessing the human tendencies to behave efficiently with the environment. Aligned with the SDT framework, Vallerand (1997) developed the hierarchical model of intrinsic and extrinsic motivation (HMIEM), evidencing the influence of social factors on the three basic psychological needs (BPN; autonomy, competence, and relatedness), and its consequent impact on the way someone regulates his motivation toward a given behavior. According to this sequence, perceived autonomy (i.e. volitional choice and presentation of alternatives), competence (i.e. positive feedback), and relatedness (i.e. emotional connection) support predict BPN satisfaction. Following this causal sequence, Ryan and Deci (2017) explained that the satisfaction of all three BPN leads to more autonomous forms of motivation, in which the person values the behavior and engages in it for pleasure. Thus, feelings of autonomous motivation lead to positive outcomes such as enjoyment (Monteiro et al., 2018), well-being (Teixeira et al., 2018), and positive affect (Schneider and Kwan, 2013).

\section{Literature review in exercise participation}

Motivational and cognitive antecedents on healthrelated behaviors have been pointed out as major contributors to exercise adherence (Ntoumanis et al., 2017). However, only parts of the HMIEM causal sequence have been tested in the exercise context. For example, only perceived autonomy support has been identified as a predictor of all BPN (Ng et al., 2013). Since perceived interpersonal behavior includes three distinct constructs, each one directly related with the respective need (Ryan and Deci, 2017), it seems pertinent to fill in this research gap by considering all three supportive interpersonal behaviors.

Nevertheless, the prediction of BPN satisfaction on autonomous motivation may have the most consistent relationship in the exercise context, as proven by theoretical (Rodrigues et al., 2018; Teixeira et al., 2012) and empirical studies (Moreno-Murcia et al., 2017; Ntoumanis et al., 2017). Specifically, higher levels of autonomy, competence, and relatedness satisfaction are more likely to lead to autonomous forms of motivation (i.e. identified, integrated, and intrinsic motivation).

Although past literature shows positive prediction of autonomous motivation on several positive outcomes, enjoyment has been little studied in the context of physical exercise (Puente and Anshel, 2010). In similar contexts such as sports (Monteiro et al., 2018; Pulido et al., 2014) and physical education (Gråstén and Watt, 2017; Navarro-Patón et al., 2019), enjoyment has been pointed out as a strong forecaster of intention. In other words, individuals perceiving pleasure and joy when engaging in physical activity are more likely to intent to maintain the behavior in the future. This association is relevant since intention has been considered the proximal predictor of behavior (Ajzen, 2002; Hagger, 2019). However, in the exercise context, intention falls short on predicting health-related behaviors since past studies have 
shown only 11 percent of intentions' predictability on adherence (Gomes et al., 2017). As Hagger and Chatzisarantis (2009) claim in their review, intention does not necessarily translate into action, suggesting a power of only 20 to 30 percent on variance toward the behavior. In other words, there is a gap of 80 to 70 percent which is still unexplained. Recently, Hagger (2019) claimed the need to introduce other constructs when attempting to more efficiently explain and understand future behavior.

Past behavior has a predictive power and is strongly related with future behavior (Albarracín and Wyer, 2000; Sommer, 2011). Nevertheless, it has not yet been considered in the context of exercise or in the context of physical activity. Past behavior can be defined as the frequency a person acts on a given stimuli. The more a person repeats the behavior, the more likely the person is to perform the behavior in the future (Hagger et al., 2002). Several studies evidence that past behavior directly predicts future behavior (REF). As a matter of fact, Sommer (2011) argues that past behavior might be a better predictor for future behavior than intention. Thus, in the context under analysis, one could hypothesize that exercisers' past exercise experience (e.g. frequency) will have a stronger impact on exerciser's future behavior than their present intention to engage in future exercise participation. Hence, the inclusion of past behavior on the HMIEM sequence could bring innovate insights to the prediction of exercisers' future behavior and allow to compare its impact with motivational and cognitive antecedents.

Up until today, studies considering the full causal sequence of HMIEM in the exercise context are scarce (Kowal and Fortier, 2000; Puente and Anshel, 2010), and existing research does not even consider past behavior as possible predictor of future behavior. Other studies have tested the proposed sequence based on SDT without considering BPN satisfaction (MorenoMurcia et al., 2018; Ramis et al., 2017), which proves to be controversial since BPN play a crucial mediation role between individuals' perception of social factors and their motivation toward a given behavior (Ryan and Deci, 2017).
Hence, this study pretends to extend the HMIEM sequence, by including enjoyment, intention toward exercising, and past behavior as predictors of exercise adherence. This represents an innovative way to identify the determinants that better predict the way gym members will behave in the future. In fact, several authors (Ntoumanis et al., 2017; Rodrigues et al., 2018) have recently stated the need of more studies in order to establish adequate recommendations regarding the systemization of behavior strategies necessary to promote significant exercise adherence in gym members.

\section{Present research}

Considering past literature and its agenda for future research, the aim of this study was to test the causal sequence of HMIEM on enjoyment, thus understanding how enjoyment predicts intention toward exercising and how intention predicts future behavior. In addition, this study aimed at testing the impact of past behavior on intention toward exercising and on future behavior itself.

The present research is significant for theoretical and empirical reasons. From a theoretical point of view, no study has previously tested the current hypothesized model, in which past behavior is considered as a predictor of future behavior, in the context of exercise. This is relevant, given the potential of this model to understand the impact past behavior has on future exercise adherence, an important yet unexplored relationship in the present domain. In a practical perspective, results from current research could provide health and exercise professionals' important insights on how behavior frequency might impact future adherence, leading them to more easily adapt the way they approach gym members depending on their exercise experience.

In sum, we hypothesize that the model without considering the past behavior will display a predictive sequence of motivational, emotional, and cognitive determinants on future behavior. One the other hand, we suspect that the addition of past behavior in the model may constrain the effect of these variables on future behavior. 


\section{Methods}

\section{Procedures and participants}

Following approval by a University Ethics Committee (CE-UBI-pJ-2018-044:ID683), several Portuguese gym managers $(n=10)$ were contacted and asked permission to collect data. After granting consent, potential participants were approached at the gym reception desk and asked to voluntarily participate in this study. Participants were recruited by convenience according to their access at the gym. The purpose and nature of the study was explained and informed consent was obtained. Researchers specifically asked for authorization to have access to frequency records since it represented the main measure of the current research. Gym exercisers, who agreed to voluntarily participate in this study, signed an informed consent and responded to a multi-section questionnaire that took approximately 25 minutes to complete. In order to be included in the final sample, exercisers needed to be aged 18 years or above, have at least 6 months of experience, and a minimum of 2 week frequency without consecutive withdrawal episodes. Data were collected between 5 August 2018 and 10 May 2019.

For this study, 293 exercisers (female $=166$; male $=127)$ aged between 18 and $65(36.57$ $\pm 11.25)$ years were enrolled for analysis. Regarding their exercise activity at the gym, 51 percent were practicing fitness group classes (e.g. indoor cycling, pump, jump) and 49 percent were engaged in cardio/resistance training. Week frequency fluctuated between 2 and $8(3.40 \pm 1.19)$ times per week and training sessions lasted between 30 and $120(61.21 \pm 14.17)$ minutes.

\section{Measures}

Perceived supportive behaviors. The Interpersonal Behavior Questionnaire (Rocchi et al., 2017), Portuguese version (Rodrigues et al., 2019), was used to assess autonomy support (four items: e.g. "My exercise physiologist supports the choices I make for myself"), competence support (four items: e.g. "My exercise physiologist encourages me to improve my skills"), and relatedness support (four items: e.g. "My exercise physiologist is interested in what I do"). Participants responded to each statement using a 7-point scale ranging from 1 ("do not agree") to 7 ("totally agree"), and a mean score for each factor was calculated. Finally, a composite factor was created, named perceived supportive behaviors, as followed by Rocchi and Pelletier (2018), showing this scale to be reliable for measuring supportive behaviors.

BPN satisfaction. The Basic Psychological Need Satisfaction and Frustration Scale (Chen et al., 2015), Portuguese version (Rodrigues et al., 2019), was used to assess autonomy (four items: e.g. "I feel that exercising reflects what I really want"), competence (four items: e.g. "I feel confident that I can do hard exercises well"), and relatedness (four items: e.g. "I feel close to the people who train with me") satisfaction. Each statement was answered using a 5-point scale ranging from 1 ("totally disagree") to 5 ("totally agree"), and a mean score for each factor was calculated. Finally, all factors were encompassed into one global factor named BPN satisfaction. Similar procedures were used supporting the use of this scale in the exercise context (Teixeira et al., 2018).

Autonomous motivation. The Behavioral Regulation in Exercise Questionnaire 3 (Cid et al., 2018) was used to assess all three autonomous forms of motivation: identified regulation (three items: e.g. "I identify myself with exercising"), integrated regulation (three items: e.g. "I consider it important to make an effort to exercise regularly"), and intrinsic motivation (three items: e.g. "I find exercise a pleasant activity"). Participants responded to each statement using a 5-point scale ranging from 0 ("not true to me") to 4 ("very true to me"). Average scores were calculated and encompassed into one factor named autonomous motivation. Similar procedures were conducted by previous studies (Cid et al., 2018; Teixeira et al., 2018) demonstrating the validity of this scale. 
Enjoyment. The Physical Activity Enjoyment Scale (Teques et al., 2018) was used to measure eight items, stating participants agreement on using a 7-point scale ranging from 1 ("totally disagree") to 7 ("totally agree"). Teques et al. (2018) have shown this scale to be reliable and presented consistent results.

Intention. Ajzen (2006) recommendations were followed for creating three items to measure intention to act upon exercise during next 6 months: "I will maintain present exercise frequency in the next 6 months"; "I will continue to exercise frequently in the next 6 months as I currently do"; and "I pretend to exercise in the next 6 months at the same frequency as it is practiced today." Participants responded to each statement using a 7-point scale ranging from 1 ("do not agree") to 7 ("totally agree").

Exercise behavior. Computer records were used to measure exercise frequency. Gym entries were summed up into two scores, one for the 6 months adherence prior to filling the questionnaires and one after 6 months of regular exercise. Similar procedures have been used in the literature (Gomes et al., 2017) and observable measures are more reliable than self-reported questionnaires (Liu et al., 2016).

\section{Statistical analysis}

In total, data from 567 exercisers (female $=345$; male $=222$ ) were collected. However, after a preliminary analysis, data from 140 participants were eliminated because they had dropped out, 75 participants had enrolled in current fitness centers for less than 6 months, and 59 had less than 2-week exercise frequency. Afterwards, data with less than 5 percent of missing values were imputed using Multiple Imputation procedures (Allison, 2000). Participants with more than 5 percent of missing values, possible univariate $(z>3.00)$ and multivariate $\left(D^{2}=p 1<.001, p 2<.001\right)$ outliers were excluded, following Byrne (2016) guidelines.

A structural equation modeling (SEM) using IBM SPSS AMOS v23 according to Kline
(2016) recommendations was performed. Thus, before performing SEM, variance inflation factor (VIF) analysis was conducted to test for collinearity issues. Values less than 10 reject possible collinearity, moving ahead to test regression model (Hair et al., 2014). Following Nevitt and Hancock (2001) recommendations, a Bollen-Stine (B-S) bootstrap of 2000 samples in SEM will be imputed if multivariate kurtosis coefficient would exceed expected values $(>5)$. The following indexes were used for analyzing structural model fit: comparative fit index (CFI), Tucker-Lewis Index (TLI), standardized root mean square residual (SRMR), and root mean square error of approximation (RMSEA) and its $90 \%$ confidence interval (CI) (see Table 1$)$. For these indexes, scores of CFI and TLI $\geqslant .90$, SRMR and RMSEA $\leqslant .8$ were considered suitable (Hair et al., 2014; Marsh et al., 2004). In addition, direct and indirect effects were considered for analysis, considering 90\% CI.

\section{Results}

\section{Preliminary analysis}

Data were imputed in 10 questionnaires that presented missing values less than 3 percent. Questionnaires, displaying missing values more than 5 percent, were eliminated. Dataset was screened for univariate and multivariate outliers. One univariate outlier was identified and consequently excluded from further analysis. Descriptive statistics and bivariate correlations are displayed in Table 2. Results show positive and significant associations between constructs, except for perceived supportive behaviors and BPN satisfaction with past and future behavior.

\section{SEM}

A B-S bootstrap of 2000 samples was imputed since multivariate kurtosis exceeded cutoffs. VIF presented scores below 2, rejecting possible collinearity issues, thus moving ahead for SEM analysis. The hypothesized structural model fit the data acceptably, considering or not past behavior. The structural path estimates were in line with 
Table I. Model fit indexes in SEM.[AQ: 2]

\begin{tabular}{|c|c|c|c|c|c|c|c|c|c|c|}
\hline & \multirow[t]{2}{*}{$\chi^{2}$} & \multirow[t]{2}{*}{$d f$} & \multirow[t]{2}{*}{$\chi^{2} / d f$} & \multirow[t]{2}{*}{ B-S } & \multirow[t]{2}{*}{$\mathrm{CFI}$} & \multirow[t]{2}{*}{ TLI } & \multirow[t]{2}{*}{ SRMR } & \multirow[t]{2}{*}{ RMSEA } & \multicolumn{2}{|c|}{ RMSEA $90 \% \mathrm{Cl}$} \\
\hline & & & & & & & & & Lower & Upper \\
\hline SEM without past behavior & 534.405 & 185 & 2.889 & $<.001$ & .925 & .915 & .076 & .080 & .073 & .088 \\
\hline SEM with past behavior & $577.44 I$ & 204 & 2.831 & $<.001$ & .929 & .920 & .080 & .079 & .075 & .087 \\
\hline
\end{tabular}

B-S: Bollen-Stine bootstrap significance; CFI: comparative fit index; TLI: Tucker-Lewis Index; SRMR: standard root mean residual; RMSEA: root mean square error of approximation; $\mathrm{Cl}$ : confidence interval; SEM: structural equation modeling.

Table 2. Descriptive statistics and correlation matrix between constructs.

\begin{tabular}{|c|c|c|c|c|c|c|c|c|c|}
\hline & \multirow[t]{2}{*}{ M } & \multirow[t]{2}{*}{$S D$} & \multicolumn{7}{|c|}{ Correlation matrix } \\
\hline & & & $\mathrm{I}$. & 2. & 3. & 4. & 5. & 6. & 7. \\
\hline I. Perceived supportive behaviors & 5.26 & 0.79 & I & & & & & & \\
\hline 2. BPN satisfaction & 4.05 & 0.48 & $.64 * *$ & 1 & & & & & \\
\hline 3. Autonomous motivation & 3.33 & 0.46 & $.51 * *$ & $.63 * *$ & 1 & & & & \\
\hline 4. Enjoyment & 4.47 & 0.69 & $.52 * *$ & $.64 * *$ & $.68 * *$ & I & & & \\
\hline 5. Intention & 5.72 & 0.87 & $.30 * *$ & $.36 * *$ & $.42 * *$ & $.40 * *$ & I & & \\
\hline 6. Past behavior & 69.31 & 29.46 & .04 & .02 & $.27 * *$ & $.14 *$ & $.20 * *$ & 1 & \\
\hline 7. Future behavior & 67.48 & 31.22 & .02 & .04 & $.28 * *$ & $.15^{*}$ & $.22 * *$ & $.93 * *$ & I \\
\hline
\end{tabular}

BPN: basic psychological needs.

$* p=.05 ; * * p=.01$.

proposed hypothesis: positive associations were observed in the relationship between: (a) perceived supportive behavior and BPN satisfaction, (b) BPN satisfaction and autonomous motivation, (c) autonomous motivation and enjoyment, (d) enjoyment and intention, and (e) intention and future behavior. However, adding past behavior to the model offsets intention's significance on future behavior, turning past behavior to be strongly significant on future behavior and on intention (see Figure 1 and Table 3). [AQ: 3]

Regarding indirect paths, significant indirect effects were found among all constructs under analysis in the model without past behavior. However, once again, the addition of past behavior in the model (see Table 3) eliminates all indirect effect from all constructs on future behavior.

\section{Discussion}

This study was designed to test an expanded HMIEM causal sequence based on SDT tenets, mainly focusing on the prediction of past behavior on intention toward future exercise participation and on the behavior itself. The findings provide strong support for the HMIEM causal sequence, as theoretically expected. In fact, the extended model (i.e. perceived supportive behaviorsBPN satisfaction - autonomous motivationenjoyment-intention - futurebehavior)corroborates past literature (Gardner et al., 2017; Monteiro et al., 2018). Interestingly, the insertion of past behavior changes all significant predictions. Results will be discussed according to existing literature.

The current study shows that gym members perceiving fitness professionals as supportive report higher levels of BPN satisfaction, in line with findings from previous research in the exercise context (Edmunds et al., 2008; Ntoumanis et al., 2017). Hence, the satisfaction of autonomy, competence, and relatedness forecasted autonomous motivation, which in turn, displayed significance with enjoyment. Past theoretical (Rodrigues et al., 2018; Ryan and 


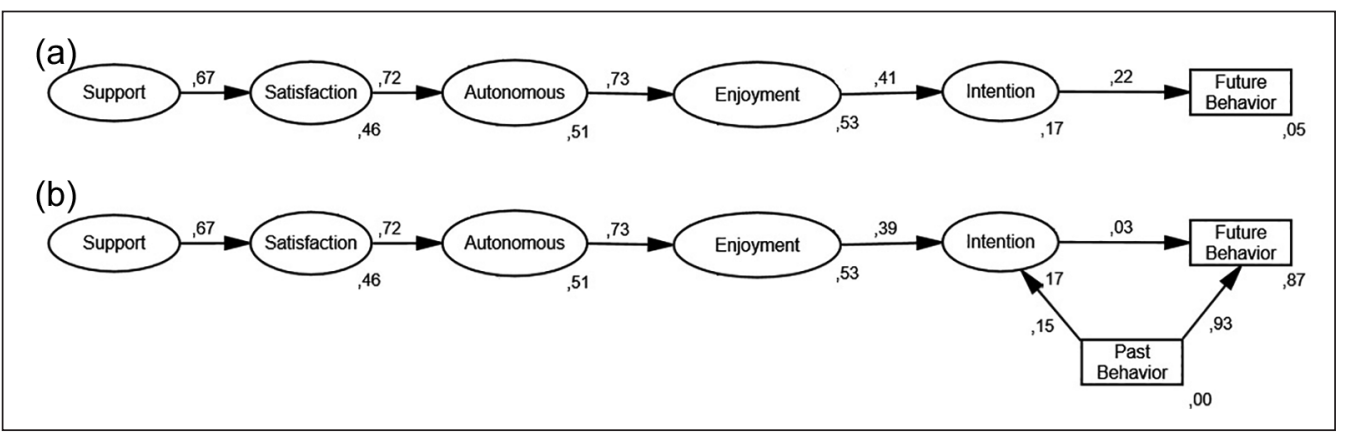

Figure I. Structural model (a) without past behavior and (b) with past behavior.

Deci, 2017) and empirical studies in the context of exercise (Puente and Anshel, 2010), sport (Pulido et al., 2014), and physical education (Navarro-Patón et al., 2019) corroborate these findings, highlighting the importance of social factors on emotional outcomes. Enjoyment was associated with intention, and finally, future exercise adherence was projected by positive significance of intention. Research assessing the association between enjoyment and intention is scarce. However, the findings from this study are aligned with the previous one, identifying the need to feel pleasure and joy when exercising as a factor promoting a sense of intention to act on the behavior in the future (Gardner et al., 2017; Monteiro et al., 2018). Intention on present participants in a 1-year longitudinal design displayed variance of only 5 percent on future behavior. These results are quite below the 11 percent observed by Gomes et al. (2017) or the 20 to 30 percent interval identified by Hagger and Chatzisarantis (2009). Current results could be explained by the exercise experience gym members already had. Since individuals had more than 1-year of regular exercise practice, their intentions toward exercising might have diminished since exercise practice had already become a part of their routine activities. Routine behaviors are generally defined as actions or reactions controlled by habits (Gardner, 2015), which can attenuate the significance of intention and its predication on future behavior. In other words, the degree to which someone has acted on the behavior in the past will determine its repetition in the future, as shown in past research (Rhodes et al., 2003).

\section{Beyond motivational antecedents for future exercise participation}

The addition of past behavior to the HMIEM model has shown to offset direct and indirect effect of all constructs under analysis on future behavior. Current findings suggest past behavior to be a powerful predictor of future exercise adherence, corroborating with past literature (Hagger, 2019; Hagger et al., 2018; Sheeran and Webb, 2016; Sommer, 2011). It is worth to mention that as reported by Kidwell and Jewell (2008), past behavior did exhibited a significant positive effect on intention. However, it did not exert a significant indirect effect via intention on future exercise adherence. These results are in line with previous research (Hagger, 2019; Hagger et al., 2018). On the one hand, literature indicates that greater experience serves to stabilize intention, meaning that the person will more likely act on the behavior (Ajzen, 2002; Sheeran et al., 1999). On the other hand, studies on habits indicate that higher past experience reduces intention-behavior since repeating relevant contextual cues prompts the behavior routinely (Albarracín and Wyer, 2000; Ouellette and Wood, 1998; Sommer, 2011). As stated by Loehr et al. (2014), outcome expectations for exercise participation could vary over time, being associated with individuals' experience. In this sense, repeated behavior performance 
Table 3. Path estimates among constructs.

\begin{tabular}{|c|c|c|c|c|c|}
\hline \multirow[t]{2}{*}{ Path } & \multirow[t]{2}{*}{$\beta$} & \multirow[t]{2}{*}{$R^{2}$} & \multirow[t]{2}{*}{$p$-value } & \multicolumn{2}{|l|}{$95 \% \mathrm{Cl}$} \\
\hline & & & & Lower & Upper \\
\hline \multicolumn{6}{|l|}{ Direct effect } \\
\hline \multicolumn{6}{|l|}{ Without past behavior } \\
\hline Perceived supportive behavior $\rightarrow$ BPN satisfaction & .66 & .46 & .001 & .54 & .78 \\
\hline BPN satisfaction $\rightarrow$ autonomous motivation & .72 & .51 & .001 & .58 & .82 \\
\hline Autonomous motivation $\rightarrow$ enjoyment & .73 & .53 & .001 & .63 & .81 \\
\hline Enjoyment $\rightarrow$ intention & .41 & .17 & .001 & .30 & .50 \\
\hline Intention $\rightarrow$ future behavior & .22 & .05 & .002 & .11 & .31 \\
\hline \multicolumn{6}{|l|}{ With past behavior } \\
\hline Perceived supportive behavior $\rightarrow$ BPN satisfaction & .67 & .46 & .001 & .54 & .78 \\
\hline BPN satisfaction $\rightarrow$ autonomous motivation & .72 & .51 & .001 & .58 & .82 \\
\hline Autonomous motivation $\rightarrow$ enjoyment & .73 & .53 & .001 & .63 & .81 \\
\hline Enjoyment $\rightarrow$ intention & .39 & .17 & .001 & .28 & .49 \\
\hline Intention $\rightarrow$ future behavior & .03 & .00 & .182 & -.01 & .06 \\
\hline Past behavior $\rightarrow$ intention & .15 & .02 & .002 & .06 & .23 \\
\hline Past behavior $\rightarrow$ future behavior & .93 & .86 & .001 & .90 & .95 \\
\hline \multicolumn{6}{|l|}{ Indirect effect } \\
\hline \multicolumn{6}{|l|}{ Without past behavior } \\
\hline $\begin{array}{l}\text { Perceived supportive behavior } \rightarrow \text { autonomous } \\
\text { motivation }\end{array}$ & .48 & .23 & .001 & .34 & .01 \\
\hline Perceived supportive behavior $\rightarrow$ enjoyment & .35 & .12 & .001 & .23 & .47 \\
\hline Perceived supportive behavior $\rightarrow$ & .14 & .02 & .001 & .09 & .21 \\
\hline Perceived supportive behavior $\rightarrow$ future behavior & .03 & .00 & .001 & .02 & .06 \\
\hline BPN satisfaction $\rightarrow$ enjoyment & .52 & .27 & .001 & .38 & .64 \\
\hline BPN satisfaction $\rightarrow$ intention & .21 & .04 & .001 & .14 & .30 \\
\hline BPN satisfaction $\rightarrow$ future behavior & .05 & .00 & .001 & .02 & .08 \\
\hline Autonomous motivation $\rightarrow$ intention & .30 & .09 & .001 & .22 & .39 \\
\hline Autonomous motivation $\rightarrow$ future behavior & .06 & .00 & .001 & .03 & .10 \\
\hline Enjoyment $\rightarrow$ future behavior & .09 & .01 & .001 & .05 & .14 \\
\hline \multicolumn{6}{|l|}{ With past behavior } \\
\hline $\begin{array}{l}\text { Perceived supportive behavior } \rightarrow \text { autonomous } \\
\text { motivation }\end{array}$ & .48 & .23 & .001 & .34 & .61 \\
\hline Perceived supportive behavior $\rightarrow$ enjoyment & .35 & .12 & .001 & .23 & .47 \\
\hline Perceived supportive behavior $\rightarrow$ intention & .14 & .2 & .001 & .08 & .21 \\
\hline Perceived supportive behavior $\rightarrow$ future behavior & .00 & .00 & .135 & -.01 & .01 \\
\hline BPN satisfaction $\rightarrow$ enjoyment & .52 & .27 & .001 & .38 & .64 \\
\hline BPN satisfaction $\rightarrow$ intention & .20 & .04 & .001 & .12 & .29 \\
\hline BPN satisfaction $\rightarrow$ future behavior & .01 & .00 & .143 & -.01 & .02 \\
\hline Autonomous motivation $\rightarrow$ intention & .28 & .08 & .001 & .20 & .37 \\
\hline Autonomous motivation $\rightarrow$ future behavior & .01 & .00 & .155 & -.01 & .02 \\
\hline Enjoyment $\rightarrow$ future behavior & .01 & .00 & .159 & -.01 & .03 \\
\hline Past behavior $\rightarrow$ future behavior & .00 & .00 & .116 & -.01 & .01 \\
\hline
\end{tabular}

$\mathrm{Cl}$ : confidence interval; BPN: basic psychological needs.[AQ: 4] 
could bypass intention, nullifying its effect of engaging in regular physical exercise in the future.

Several authors (Hagger et al., 2018; Ouellette and Wood, 1998) assume that past behavior reliably reflects habitual behavior in several settings. Performing inconsistently (e.g. withdrawal episodes or procrastination to exercise) or having unpleasant experiences (e.g. perceived thwarting behaviors by fitness professionals) could undermine the intention to repeat the behavior. In this research, 120 individuals were eliminated from analysis for having withdrawal episodes or dropping-out. While we did not measure the reasons for this behavior, literature suggests controlling and thwarting behaviors to be responsible for negative outcomes (Bartholomew et al., 2011; Rocchi and Pelletier, 2018; Ryan and Deci, 2017). Moreover, external (e.g. atypical work shifts) and internal (e.g. skipping training session to go to the movies) factors may prevent its repetition.

Albarracín and Wyer (2000) have reported the lack of evidence of separating the effects of a person's past behavior from the effects of motivational and cognitive factors that accompany the decision to engage in a certain behavior. Current findings suggest the override power of past behavior on motivational antecedents when it comes to measuring exercise adherence. This is novel since literature has confirmed the importance of both motivational tenets (e.g. behavioral regulation), cognitive factors (e.g. intention), and frequency (e.g. past behavior) as positive and significant predictors of future behavior (Hagger and Chatzisarantis, 2009). But, when everyone is at stake, past behavior takes the "trophy," by explaining 86 percent of variance in future behavior, whereas perceived supportive behaviors, BPN satisfaction, autonomous motivation, enjoyment, and intention are not even significant.

\section{Conclusion}

\section{Limitations}

Although the present findings contribute with relevant information about the nullifying effect of past behavior on intention and future behavior, it is important to consider some limitations. No intervention was induced on the sample, preventing the establishment of causal relationship. In addition, the specific context design and cultural background precludes generalization. Forthcoming experimental studies are needed to address the role of supportive versus thwarting interpersonal behaviors on gym clients exercise adherence. Furthermore, it would be interesting for new studies to analyze the "dark" side of motivation on exercise-related behavior. It seems that thwarting behaviors could promote BPN frustration, leading to controlled forms of motivation, or even amotivation (Rocchi and Pelletier, 2018; Rodrigues et al., 2018).

In addition, some participants had 40 years of exercise experience, potentially influencing present findings. The proposed model should be applied to new gym members, in order to longitudinally study their adherence regularly over a 1-year course. Interesting results could emerge and comparison with current results is of relevance.

Finally, applying this model to exercisers displaying different physical activity levels, including the measurement of habit development, could bring new insights. It seems that past behavior could be related to exercise habit formation, provided by specific external (e.g. preparing gym bag the previous day) or internal cues (i.e. visualizing mentally tomorrow's training session; motivational regulation) over a specific period of time (Hagger, 2019).

\section{Practical implications}

Beyond doubt, considerable research work lies ahead. Future studies should address past behavior as a predictor of future behavior when analyzing exercise-related behavior. Motivational determinants are essential for assessing intention and behavioral outcomes; however, as seen in the present study, past behavior has the capability to override this effect. In addition, on the long-term, motivation can shift leading to differentiated results, as shown by past literature (Ingledew and Markland, 2008). Fitness professionals should augment their attention with new gym 
clients and those with less than 6-months of experience, since they have a higher chance of withdrawal. Supportive behaviors are essential to promote exercise as an integral part of someone's daily activities. Individuals with more than 1-year of regular exercise practice are still at stake when it comes to dropping-out, but they have a "background" to hold them up and make them remain accountable to maintain exercise commitment. In addition, the fitness industry should promote a minimal exercise frequency of two times per week, without withdrawal episodes, since present findings suggest that individuals practicing exercise two times per week are more likely to keep on exercising in the future.

In sum, past behavior, an under-researched construct in the assessment of exercise adherence, seems to be a significant positive forecaster of future behavior. Current study shows that, independently of exerciser's perception of supportive behaviors, BPN satisfaction, autonomous motivation, enjoyment, and intentions toward exercising in the future, experience has a stronger prediction on how exercisers will behave in the future.

\section{Declaration of conflicting interests[GQ: 2]}

The author(s) declared no potential conflicts of interest with respect to the research, authorship, and/or publication of this article.

\section{Funding}

The author(s) received no financial support for the research, authorship, and/or publication of this article.

\section{ORCID iD[GQ: 3]}

Filipe Rodrigues (iD https://orcid.org/0000-0003 $-1327-8872$

\section{References}

Ajzen I (2002) Residual effects of past on later behavior: Habituation and reasoned action perspectives. Personality \& Social Psychology Review 6(2): 107-122.

Ajzen I (2006) Constructing a TPB questionnaire: Conceptual and methodological considerations.
Available at: http://www-unix.oit.umass.edu / aizen (accessed 14 March 2019).

Albarracín D and Wyer R (2000) The cognitive impact of past behavior: Influences beliefs, attitudes, and future behavioral decisions. Journal of Personality \& Social Psychology 79(1): 5-22.

Allison P (2000) Multiple imputation for missing data: A cautionary tale. Sociological Methods \& Research 28(3): 301-309.

Bartholomew K, Ntoumanis N, Ryan R, et al. (2011) Psychological need thwarting in the sport context: Assessing the darker side of athletic experience. Journal of Sport and Exercise Psychology 1: 75-102.

Byrne B (2016) Structural Equation Modeling with AMOS. Basic Concepts, Applications, and Programming (3rd edn). New York: Taylor \& Francis Group.

Chen B, Vansteenkiste M, Beyers W, et al. (2015) Basic psychological need satisfaction, need frustration, and need strength across four cultures. Motivation \& Emotion 39(2): 216-236.

Cid L, Monteiro D, Teixeira D, et al. (2018) The Behavioral Regulation in Exercise Questionnaire (BREQ-3) Portuguese-Version: Evidence of reliability, validity and invariance across gender. Frontiers in Psychology 9: 1940.

Deci E and Ryan R (1985) Intrinsic Motivation and Self-Determination in Human Behavior. New York: Plenum Press.

EC (2018) Special Eurobarometer 472-Sport and physicalactivity. Availableat:http://data.europa. eu/euodp/data/dataset/S2164_88_4_472_ENG (accessed 26 September 2019).[AQ: 5]

Edmunds J, Ntoumanis N and Duda J (2008) Testing a self-determination theory-based teaching style intervention in the exercise domain. European Journal of Social Psychology 38(2): 375-388.

Gardner B (2015) A review and analysis of the use of "habit" in understanding, predicting and influencing health-related behaviour. Health Psychology Review 9(3): 277-295.

Gardner L, Magee C and Vella S (2017) Enjoyment and behavioral intention predict organized youth sport participation and dropout. Journal of Physical Activity \& Health 14(11): 861-865.

Gomes A, Gonçalves A, Maddux J, et al. (2017) The intention-behaviour gap: An empirical examination of an integrative perspective to explain exercise behaviour. International Journal of Sport and Exercise Psychology 16(6): 607-621. 
Gråstén A and Watt A (2017) A motivational model of physical education and links to enjoyment, knowledge, performance, total physical activity and body mass index. Journal of Sports Science \& Medicine 16: 318-327.

Hagger M (2019) Habit and physical activity: Theoretical advances, practical implications, and agenda for future research. Psychology of Sport and Exercise 42: 118-129.

Hagger M and Chatzisarantis N (2009) Integrating the theory of planned behaviour and self-determination theory in health behaviour: A metaanalysis. British Journal of Health Psychology 14(2): 275-302.

Hagger M, Chatzisarantis N and Biddle S (2002) A meta-analytic review of the theories of reasoned action and planned behavior in physical activity: Predictive validity and the contribution of additional variables. Journal of Sport and Exercise Psychology 24(1): 3-32.

Hagger M, Polet J and Lintunen T (2018) The reasoned action approach applied to health behavior: Role of past behavior and tests of some key moderators using meta-analytic structural equation modeling. Social Science \& Medicine 213: 85-94.

Hair J, Black W, Babin B, et al. (2014) Multivariate Data Analysis (7th edn). Upper Saddle River, NJ: Pearson Educational, Inc.

Ingledew D and Markland D (2008) The role of motives in exercise participation. Psychology \& Health 23(7): 807-828.

Kidwell B and Jewell R (2008) The influence of past behavior on behavioral intent: An information-processing explanation. Psychology \& Marketing 25(12): 1151-1166.

Kline R (2016) Principles and Practice of Structural Equation Modelling (3rd edn). New York: Guildford Press.

Kowal J and Fortier M (2000) Testing relationships from the Hierarchical Model of Intrinsic and Extrinsic Motivation using flow as a motivational consequence. Research Quarterly for Exercise \& Sport 71(2): 171-181.

Lee I, Shiroma E, Lobelo F, et al. (2012) Effect of physical inactivity on major non-communicable diseases worldwide: An analysis of burden of disease and life expectancy. The Lancet 380 (9838): 219-229.

Liu S, Driban J, Eaton C, et al. (2016) Objectively measured physical activity and symptoms change in knee osteoarthritis. American Journal of Medicine 129(5): 497-505.e491.
Loehr V, Baldwin A, Rosenfield D, et al. (2014) Weekly variability in outcome expectations: Examining associations with related physical activity experiences during physical activity initiation. Journal of Health Psychology 19(10): 1309-1319.

Marsh H, Hau K and Wen Z (2004) In search of Golden Rules: Comment on hypothesis-testing approaches to setting cutoff values for fit indexes and dangers in overgeneralizing $\mathrm{Hu}$ and Bentler's (1999) Findings. Structural Equation Modeling: A Multidisciplinary Journal 11(3): 320-341.

Monteiro D, Pelletier L, Moutão J, et al. (2018) Examining the motivational determinants of enjoyment and the intention to continue of persistent competitive swimmers. International Journal of Sport Psychology 49(6): 484504.

Moreno-Murcia J, Belando N, Huéscar E, et al. (2017) Social support, physical exercise and life satisfaction in women. Revista Latinoamericana de Psicología 49(3): 194-202.

Moreno-Murcia J, Huescar Hernandez E and Ruiz L (2018) Perceptions of controlling teaching behaviors and the effects on the motivation and behavior of high school physical education students. International Journal of Environmental Research \& Public Health 15(10): E2288.

Navarro-Patón R, Lago-Ballesteros J, BasantaCamiño S, et al. (2019) Relation between motivation and enjoyment in physical education classes in children from 10 to 12 years old. Journal of Human Sport and Exercise 14(3): 527-537.

Nevitt J and Hancock G (2001) Performance of Bootstrapping approaches to model test statistics and parameter standard error estimation in Structural Equation Modeling. Structural Equation Modeling: A Multidisciplinary Journal 8(3): 353-377.

$\mathrm{Ng} \mathrm{J}$, Ntoumanis $\mathrm{N}$, Thogersen-Ntoumani C, et al. (2013) Predicting psychological needs and well-being of individuals engaging in weight management: The role of important others. Applied Psychology in Health \& Well-Being 5(3): 291-310.

Ntoumanis N, Thogersen-Ntoumani C, Quested E, et al. (2017) The effects of training group exercise class instructors to adopt a motivationally adaptive communication style. Scandinavian Journal of Medicine \& Science in Sports 27(9): 1026-1034. 
Ouellette J and Wood W (1998) Habit and intention in everyday life: The multiple processes by which past behavior predicts future behavior. Psychological Bulletin 124(1): 54-74.

PAC (2019) 2019 Physical Activity Council's overview report on U.S. participation. Available at: http://www.physicalactivitycouncil.com/pdfs /current.pdf (accessed 6 October 2019).[AQ: 6]

Puente R and Anshel M (2010) Exercisers' perceptions of their fitness instructor's interacting style, perceived competence, and autonomy as a function of self-determined regulation to exercise, enjoyment, affect, and exercise frequency. Scandinavian Journal of Psychology 51(1): 38-45.

Pulido J, Sanchez-Oliva D, Amado D, et al. (2014) Influence of motivational processes on enjoyment, boredom and intention to persist in young sportspersons. South African Journal for Research in Sport, Physical Education and Recreation 36(3): 135-149.

Ramis Y, Torregrosa M, Viladrich C, et al. (2017) The effect of coaches' controlling style on the competitive anxiety of young athletes. Frontiers in Psychology 8: 572.

Rhodes R, Courneya K and Jones L (2003) Translating exercise intentions into behavior: Personality and social cognitive correlates. Journal of Health Psychology 7(4): 447-458.

Rocchi M and Pelletier L (2018) How does coaches' reported interpersonal behavior align with athletes' perceptions? Consequences for female athletes' psychological needs in sport. Sport, Exercise, \& Performance Psychology 7(2): 141-154.

Rocchi M, Pelletier L, Cheung S, et al. (2017) Assessing need-supportive and need-thwarting interpersonal behaviours: The Interpersonal Behaviours Questionnaire (IBQ). Personality \& Individual Differences 104: 423-433.

Rodrigues F, Bento T, Cid L, et al. (2018) Can interpersonal behavior influence the persistence and adherence to physical exercise practice in adults? A systematic review. Frontiers in Psychology 9: 2141.

Rodrigues F, Hair J, Neiva H, et al. (2019a) The Basic Psychological Need Satisfaction and Frustration Scale in Exercise (BPNSFS-E): Validity, reliability, and gender invariance in Portuguese exercisers. Perceptual and Motor Skills 126: 949-972.[AQ: 7]
Rodrigues F, Pelletier L, Neiva H, et al. (2019b) Initial validation of the Interpersonal Behavior Questionnaire (IBQ \& IBQ-Self) in the context of exercise: Measurement invariance and latent mean differences. Current Psychology. Epub ahead of print 15 July. DOI: $10.1007 /$ s12144019-00374-y.

Ryan R and Deci E (2017) Self-Determination Theory. Basic Psychological Needs in Motivation, Development, and Wellness. New York: Guildford Press.

Schneider M and Kwan B (2013) Psychological need satisfaction, intrinsic motivation and affective response to exercise in adolescents. Psychology of Sport and Exercise 14(5): 776-785.

Sheeran P and Webb T (2016) The intention-behavior gap. Social \& Personality Psychology Compass 10(9): 503-518.

Sheeran P, Orbell S and Trafimow D (1999) Does the temporal stability of behavioral intentions moderate intention-behavior and past behaviorfuture behavior relations? Personality \& Social Psychology Bulletin 25(6): 724.

Sommer L (2011) The theory of planned behaviour and the impact of past behaviour. International Business \& Economics Research Journal 10(1): 91-110.

Teixeira D, Silva M and Palmeira A (2018) How does frustration make you feel? A motivational analysis in exercise context. Motivation \& Emotion 42(3): 419-428.

Teixeira P, Carraca E, Markland D, et al. (2012) Exercise, physical activity, and self-determination theory: A systematic review. International Journal of Behavioral Nutrition \& Physical Activity 9: 78.

Teques P, Calmeiro L, Martins H, et al. (2018) Mediating effects of parents' coping strategies on the relationship between parents' emotional intelligence and sideline verbal behaviors in youth soccer. Journal of Sport and Exercise Psychology 40(3): 153-162.

Vallerand R (1997) Toward a hierarchical model of intrinsic and extrinsic motivation. Advances in Experimental Social Psychology 29: 271-360.

WHO (2019) Global action plan on physical activity 2018-2030. Available at: https://www.who .int/ncds/prevention/physical-activity/global -action-plan-2018-2030/en/ (accessed 4 October 2019).[AQ: 8] 